\title{
The Effect of Kinesio Taping Pre-intervention on Delayed Onset Muscle Soreness
}

\author{
Jae Cheol Park, Mi Sook Park, Tae Yeun Hwang \\ Department of Physical Therapy, Chunnam Techno University, Gokseong, Korea
}

Purpose: This examined the effect of Kinesio taping pre-intervention on the pain, tenderness, proprioceptive sensation, and muscle strength associated with delayed onset muscle soreness.

Methods: Thirty subjects were divided into a Kinesio taping application group of 15 subjects and a control non-taped group of 15 subjects, and the changes in individual variables were analyzed before taping and at 24, 48, and 72 hours after taping using two-way repeated ANOVA. Post-hoc t-tests were conducted in the cases with intergroup interactions, and the significance level a was set to $\alpha=0.01$.

Results: The changes in pain during rest were significantly different only for the times, while the changes in pain during exercise were significantly different for the times, interactions between the times and groups, and intergroup changes $(p<0.05)$. The changes in tenderness were significantly different for the times and for interactions between the times and groups $(p<0.05)$. The changes in proprioceptive sensation were significantly different for the times, interactions between times and groups, and intergroup changes $(p<0.05)$. The changes in muscle strength were significantly different only for the times $(p<0.05)$.

Conclusion: The application of Kinesio taping had positive effects on the pain, tenderness, and proprioceptive sensation of delayed onset muscle soreness. These results suggest that Kinesio taping can be a useful therapeutic factor in future studies and in clinical settings.

Keywords: Delayed onset muscle soreness, Kinesio tapping, Pressure pain, Proprioception

\section{서 론}

근력 증진을 위해 가장 많이 이용되는 운동이 저항성 운동이다. 하지 만 자신의 체력 능력과 무관하게 높은 강도의 운동을 실시하거나 새 로운 운동을 접할 때 운동 상해와 근육 조직 손상이 발생할 가능성 이 높아지게 된다.1,2 근육 손상이 발생하면 휴식과 운동 시 통증이 발 생하고 일상생활에 제약이 뒤따른다. ${ }^{3}$ 이러한 증상과 제약을 유발하 는 질환은 급성 근육통과 지연성 근육통(delayed onset muscle soreness, DOMS)으로 나뉜다. 급성 근육통은 격한 운동 후 혈류의 산소 결핍으로 발생하고 적절한 혈류와 산소 공급이 이루어지면 운동 후 빨리 사라져 큰 문제가 발생하지 않지만 DOMS는 다르다. ${ }^{4}$ 구심성 수 축(concentric contraction)보다 편심성 수축(eccentric contraction)에서 자주 발생하는 DOMS는 신장성 저항 운동, 내리막 달리기 ${ }^{6}$ 등 편심 성 수축으로 구성된 운동으로 근섬유 손상이 발생하여 여러 부정적 인 증상이 발생한다. 주요 증상으로는 근력 소실, 통증, 종창(swell- ing), 압통(tenderness), 뻣뻣함(stiffness)이 있으며,' 기능 손상과 관절 운동, 순발력, 가동범위 감소, 비대칭, 조직의 질감 변화, 운동 중 부상 등과 같이 여러 위험 요인을 포함하고 있다. ${ }^{8}$ 이러한 증상들은 운동 후 12-24시간 이내 발생하여 24-48시간 내에 최고조에 도달하고 10-14 일 이상이 지나야 점차 사라진다. ${ }^{4}$ 소실된 근력도 정상으로 복귀하려 면 24 시간에서 2 주간의 시간이 소요된다. ${ }^{9}$ 이처럼 오랜 시간 동안 여 러 부작용과 일상생활의 제약이 뒤따르는 DOMS 증상을 감소시키 기 위해 임상에서 많은 중재가 이루어지고 있다.

대표적인 방법으로는 냉치료 및 간헐적 압박치료, ${ }^{10}$ 스포츠 마사지 적용, ${ }^{11}$ 스트레칭 적용, ${ }^{12}$ 초음파 치료, ${ }^{13}$ 미세전류자극치료, ${ }^{14}$ 고주파 치료, ${ }^{15}$ 테이핑 적용 ${ }^{16}$ 등이 이용되고 있다. 이 중 키네시오테이핑(kinesio taping)은 다른 치료 방법들에 비해 간편하고 운동 전, 후에 적용 가능하며, 1 회 적용으로 제거하지 않는 한 며칠 동안 테이핑의 효과 인 근 긴장도를 감소와 기계적 자극의 증가로 고유수용성 감각의 증 가 효과까지 기대할 수 있어 근육뼈대계와 중추신경계 물리치료에도
Received Jan 3, 2019 Revised Feb 13, 2019

Accepted Feb 27, 2019

Corresponding author Tae-Yeun Hwang

E-mail delta21kr@hanmail.net
Copylight (C)2019 The Korean Society of Physical Therapy

This is an Open Access article distribute under the terms of the Creative Commons Attribution Non-commercial License (Http:// creativecommons.org/license/by-nc/4.o.) which permits unrestricted non-commercial use, distribution, and reproduction in any medium, provided the original work is properly cited. 
자주 활용되고 있다.1718 또한 일반 운동 선수들이나 일반인들에게 운 동과 일생생활을 하기 전에 부상 위험도를 감소시키기 위해 많이 적 용하고 있는 실정이다. 이러한 키네시오 테이핑 선행연구로는 근. 뼈 대계 질환인 목빗근 근막 통증 환자에게 테이핑 적용이 통증과 호흡 기능에 긍정적으로 작용하였다고 보고하였고, ${ }^{19}$ 뼈관절염 환자 대상 으로 관절 가동술과 함께 테이핑 적용이 관절가동범위 회복에 도움 이 될 거라고 하였다. ${ }^{20}$ 신경계 질환에 테이핑 관련 연구를 살펴보면 마비된 앞정강근(tibialis anterior)에 테이핑을 적용하여 마비측 하지 균형 향상에 도움이 된다고 하였고, ${ }^{21}$ 또 다른 연구에서는 발등굽힘 (dorsi flexion) 시 근력 증가와 보행 속도가 증가되었다고 하였다.22 이 처럼 키네시오 테이핑에 긍정적인 효과에 대하여 많은 연구가 발표 되고 많이 이용되고 있지만 대부분 연구는 DOMS가 발생된 후 중재 에 관련된 연구들뿐이고, 본 연구처럼 DOMS 발생 전 사전 키네시오 테이핑을 적용하여 DOMS 증상이 발생했을 때의 증상 변화에 대한 연구는 부족한 실정이다.

그러므로 위팔두갈래근에 키네시오 테이핑을 적용한 후 DOMS가 발생했을 때 시기별로 각 변수에 대한 그 효과를 검증하려고 하며, 본 연구는 사전 키네시오테이핑 적용이 위팔두갈래근에 인위적으로 발 생한 DOMS의 통증, 압통, 고유수용성 감각, 근력의 변화를 분석 연구 함으로써 임상에서 기초자료와 DOMS 예방 가능성을 제시해 본다.

\section{연구 방법}

\section{1. 연구대상}

본 연구 대상자는 전남 소재 C대학에 재학중인 오른손이 비 우세손 인 20 대 30 명으로 남성 18 명, 여성 12 명을 대상으로 근육뼈대계 질환 이 없고 정기적으로 운동을 하지 않는 자로 선정하였다. 군 분류는 군 에 대한 정보를 모든 대상자에게 설명하지 않고 키네시오 테이핑 처 치군(kinesio tapping applied group, KAG) 15명, 미 처치군(no tape group, NTG) 15 명을 연구자 임의 배정방식에 의하여 무작위로 분류 를 하였고 단일맹검법(single-blind test)에 의한 대상자 선정을 하였다. 실험 전 연구의 목적과 연구 방법 등을 대상자에게 설명하고 자발적 으로 참여 의사를 밝힌 대상자로 연구동의서를 작성한 후 연구를 진

Table 1. General characteristics of subjects

\begin{tabular}{lccc}
\hline & NT $(n=15)$ & KAG $(n=15)$ & $p$ \\
\hline Age $(\mathrm{yr})$ & $22.06 \pm 1.48$ & $22.40 \pm 1.84$ & 0.159 \\
Height $(\mathrm{cm})$ & $167.80 \pm 9.14$ & $169.80 \pm 4.79$ & 0.953 \\
Weight $(\mathrm{kg})$ & $64.70 \pm 13.80$ & $62.80 \pm 8.02$ & 0.925 \\
Gender & & & \\
Male & 9 & 9 & \\
Female & 6 & 6 & \\
\hline
\end{tabular}

NT: no tape, KAG: Kinesio tapping applied group.
행하였다. 대상자의 일반적 특성인 연령, 몸무게, 신장에 대하여 동질 성 검정 결과 유의한 차이가 없어 동일한 집단임을 확인하였고, 대상 자의 일반적 특성은 다음과 같다(Table 1).

\section{2. 연구절차}

사전 키네시오테이핑 적용이 DOMS 유발로 발생하는 통증, 압통, 고 유수용성감각, 근력에 미치는 영향을 확인하고자 $\mathrm{KAG}$ 과 $\mathrm{NTG}$ 를 이 용해 모두 DOMS 유발 하루 전에 각 변수 항목을 측정하고 1 일 후 $\mathrm{KAG}$ 는 키네시오테이핑 $5 \mathrm{~cm}$; (Hygenic Corp., Akron, USA)을 위팔두 갈래근의 시작점과 끝나는 지점 범위까지 $10-15 \%$ 의 장력을 이용하여 부착한 상태에서 인위적으로 DOMS을 유발하였고, NTG는 키네시 오테이핑을 적용하지 않았다. 키네시오테이핑 적용은 일반적인 가이 드라인을 적용하였다. ${ }^{23} \mathrm{DOMS}$ 유발 방법은 최대 등척성 근력을 측정 한 후 최대 등척성 근력의 $70 \%$ 인 무게의 아령을 사용하여 대상자가 바로 선 자세에서 팔굽 관절 $90^{\circ}$ 에서 1 초간 유지한 후 3 초에 걸쳐 팔 굽 관절 완전 폄 편심성 수축 운동을 하고 다시 팔굽 관절 $90^{\circ}$ 로 위치 시킨 것을 1 회로 하여 10 회씩 7 세트를 실시하였고, 세트 간 1 분간 휴 식시간을 주었다. ${ }^{24}$ 그 후각 변수의 측정 항목을 시기별로 24 시간 후, 48시간 후, 72 시간 후에 측정하였다.

\section{3. 측정도구}

\section{1) 통증 측정}

본 연구에서는 $10 \mathrm{~cm}$ 표식이 있는 시각적 상시척도(visual analog scale, $\mathrm{VAS}$ )를 이용하여 극심한 통증을 10 , 통증이 없는 상태를 0 으로 구분 하여 환자에게 설명하고 환자 본인이 통증의 정도를 기록하게 하였 고 VAS의 측정은 휴식 시와 운동 시 각각 측정하였다. VAS는 높은 신 뢰도를 보이는 척도로 측정자내 신뢰도는 0.99 이다. ${ }^{25}$

\section{2) 압통 측정}

압통 측정을 위해서 디지털 압통 측정계(algometer, JTECH, USA)를 이용하여 오목위팔관절과 팔굽관절의 정중앙을 줄자를 이용하여 유성펜으로 표시한 후 동일 지점에서 측정하였다. 압통 측정계를 측 정 지점과 직각으로 유지하고 일정한 속도로 압력을 가하여 “아”하고 통증이 유발되는 시점을 역치 값으로 정하고 3 회 측정 후 그 평균값 을 이용하였다.

\section{3) 고유수용성감각 측정}

고유수용성 감각 측정을 위해 관절가동범위시스템(BPMpro, England)을 이용하였다. 손목에 모션센스를 착용하고 해부학적 자세에 서 팔굽관절 $60^{\circ}$ 굽힘을 눈 뜬 상태에서 확인하고 다시 눈을 감게 한 후 팔굽관절 $60^{\circ}$ 굽힘을 운동하여 자세 재현 오차각도(error angle)로 
측정하였고, 3 회 측정 후 그 평균값을 이용하였다.

\section{4) 근력 측정}

근력 측정을 위해 디지털 근력측정기(manual muscle tester, LI, USA)를 이용하였다. 이 장비는 객관적으로 근육의 힘을 정량화하기 위한 핸 드 헬드 장비로 손에 착용하고 대상자의 사지에 힘을 가하고 대상자 는 등척성 운동을 통해 근력을 측정하는 장비이다. 근력 측정 자세로 는 이 장비를 대상자가 손에 착용하고 팔걸이가 있는 의자에 앉아 팔 굽관절 $90^{\circ}$ 굽힘하여 안정화시킨 후 실험자의 근력을 측정하기 위해 책상 아래 부분에서 이 장비를 대고 책상을 들어 올려 최대 등척성 운동을 실시하였다. 1 회 측정 후 3 분간 휴식이 주어졌으며, 3 회 측정 후그 평균값을 이용하였다.

\section{4. 분석 방법}

수집된 자료는 SPSS 18.0 통계 프로그램을 이용하여 평균과 표준편 차를 산출하였고, 두 그룹의 실험 전, 24 시간 후, 48 시간 후, 72 시간 후
의 측정 변인에 대한 차이를 알아보고자 반복측정 2 요인 분산분석 (two-way repeated ANOVA)을 실시하였으며, 유의수준은 0.05로 하였 다. 시기와 군 간 상호 작용이 나타날 경우 사후분석으로 t-검정을 실 시 하였고, ${ }^{26}$ I종 오류를 줄이기 위해 유의수준 0.01 로 하였다.

\section{결 과}

\section{1. 휴식 시와 운동 시 통증의 변화}

휴식 시 통증의 변화에 대한 반복측정 2요인 분산분석 결과 시기별 로 유의한 차이가 있었으며 $(\mathrm{p}<0.05)$, 시기와 군 간 상호작용과 집단 간 변화에서 유의한 차이가 없었다 $(\mathrm{p}>0.05)$. 운동시 통증의 변화는 시기별, 시기와 군 간 상호작용과 집단 간 변화에서 유의하게 차이가 있었고 $(\mathrm{p}<0.05)$, 사후분석 결과 48 시간 후의 두 군과 72 시간 후의 두 집단간 비교에서 유의한 차이가 있었다 $(\mathrm{p}<0.01)($ Table 2).

Table 2. Comparison of state of rest VAS and state of motion VAS

\begin{tabular}{|c|c|c|c|c|c|c|c|c|}
\hline & & $\mathrm{O} \mathrm{hr}$ & $24 \mathrm{hr}$ & $48 \mathrm{hr}$ & $72 \mathrm{hr}$ & Source & $\mathrm{F}$ & $p$ \\
\hline \multirow[t]{4}{*}{ SR VAS } & KAG & 0 & $1.80 \pm 0.86$ & $1.13 \pm 1.06$ & $0.13 \pm 0.35$ & Time & $34.656^{\star \star}$ & 0.000 ** \\
\hline & NTG & 0 & $1.93 \pm 1.27$ & $1.20 \pm 0.94$ & $0.46 \pm 0.91$ & Group & 0.660 & 0.841 \\
\hline & $\mathrm{t}$ & & 0.335 & 0.182 & 1.316 & Time $\times$ Group & 0.861 & 0.716 \\
\hline & $\mathrm{p}$ & & 0.740 & 0.857 & 0.199 & & & \\
\hline \multirow[t]{4}{*}{ SM VAS } & KAG & 0 & $3.73 \pm 1.03$ & $2.80 \pm 0.67$ & $1.20 \pm 0.41$ & Time & $120.087^{\star *}$ & $0.000 * *$ \\
\hline & NTG & 0 & $4.73 \pm 1.57$ & $4.33 \pm 1.58$ & $2.46 \pm 1.55$ & Group & $14.532^{* *}$ & $0.001^{* *}$ \\
\hline & $t$ & & 2.052 & $3.440^{+}$ & $3.054^{+}$ & Time $\times$Group & $3.739^{*}$ & $0.014^{\star}$ \\
\hline & $\mathrm{p}$ & & 0.050 & $0.002^{+}$ & $0.005^{+}$ & & & \\
\hline
\end{tabular}

SR VAS: state rest visual analog scale, SM VAS: state of motion visual analog scale, KAG: kinesio tapping applied group, NTG: no tape group. ${ }^{*} p<0.05 ;{ }^{* *} p<0.001 ;$ post-hoc t-test $p<0.01$, Mean \pm SD.

Table 3. Comparison of pressure pain and proprioception, strength

$(\mathrm{Kg})(\mathrm{lb})(\mathrm{mm})$

\begin{tabular}{|c|c|c|c|c|c|c|c|c|}
\hline & & $0 \mathrm{hr}$ & $24 \mathrm{hr}$ & $48 \mathrm{hr}$ & $72 \mathrm{hr}$ & Source & $\mathrm{F}$ & $p$ \\
\hline \multirow[t]{4}{*}{ PP } & KAG & $3.14 \pm 1.00$ & $2.36 \pm 0.64$ & $2.39 \pm 0.44$ & $2.69 \pm 0.49$ & Time & $32.176^{* *}$ & $0.000^{* *}$ \\
\hline & NTG & $3.27 \pm 1.07$ & $1.81 \pm 0.70$ & $2.08 \pm 0.65$ & $2.18 \pm 0.47$ & Group & 2.123 & 0.156 \\
\hline & $\mathrm{t}$ & 0.322 & 2.233 & 1.563 & $2.878^{+}$ & Time $\times$Group & $3.088^{*}$ & $0.031^{*}$ \\
\hline & $\mathrm{p}$ & 0.749 & 0.034 & 0.129 & $0.008^{+}$ & & & \\
\hline \multirow[t]{4}{*}{ PRO } & KAG & $6.77 \pm 2.33$ & $6.20 \pm 2.83$ & $5.06 \pm 1.87$ & $3.86 \pm 1.25$ & Time & $5.730^{\star *}$ & $0.001^{* *}$ \\
\hline & NTG & $6.29 \pm 1.63$ & $7.28 \pm 2.74$ & $6.57 \pm 1.51$ & $6.35 \pm 2.18$ & Group & $4.266^{\star}$ & $0.048^{*}$ \\
\hline & $\mathrm{t}$ & 0.660 & 1.068 & 2.429 & $3.824^{+}$ & Time $\times$Group & $3.997^{\star}$ & $0.010^{*}$ \\
\hline & $\mathrm{p}$ & 0.514 & 0.295 & 0.022 & $0.001^{+}$ & & & \\
\hline \multirow[t]{4}{*}{ STR } & KAG & $13.34 \pm 6.24$ & $12.58 \pm 6.00$ & $12.78 \pm 6.23$ & $13.23 \pm 6.15$ & Time & $6.720^{\star}$ & $0.002^{*}$ \\
\hline & NTG & $13.55 \pm 5.00$ & $11.94 \pm 3.93$ & $11.74 \pm 3.43$ & $11.97 \pm 3.47$ & Group & 0.134 & 0.717 \\
\hline & $\mathrm{t}$ & 0.105 & 0.347 & 0.566 & 0.694 & Time $\times$ Group & 1.275 & 0.304 \\
\hline & $\mathrm{p}$ & 0.917 & 0.731 & 0.576 & 0.495 & & & \\
\hline
\end{tabular}

PP: pressure pain, PRO: proprioception, STR: strength, KAG: Kinesio tapping applied group, NTG: no tape group.

${ }^{*} p<0.05 ;{ }^{* *} p<0.001 ;$ post-hoc t-test $p<0.01$, Mean \pm SD. 


\section{2. 압통의 변화}

압통의 변화에 대한 반복측정 2요인 분산분석 결과 시기별, 시기와 군 간 상호작용에서 유의한 차이가 있었고 $(\mathrm{p}<0.05)$, 집단 간 변화에 서는 유의한 차이가 없었다( $\mathrm{p}>0.05)$. 사후분석 결과 72 시간 후의 두 집단간 비교에서 유의한 차이가 있었다 $(\mathrm{p}<0.01)($ Table 3$)$.

\section{3. 고유수용성 감각의 변화}

고유수용성 감각에 대한 반복측정 2 요인 분산분석 결과 시기별, 시 기와 군 간 상호작용과 집단 간 변화에서 유의한 차이가 있었다 $(\mathrm{p}<0.05)$. 사후분석 결과 72 시간 후의 두 집단 간 비교에서 유의한 차 이가 있었다 $(\mathrm{p}<0.01)($ Table 3$)$.

\section{4. 근력의 변화}

근력에 대한 반복측정 2 요인 분산분석 결과 시기별에서 유의한 차이 가 있었고 $(\mathrm{p}<0.05)$, 시기와 군 간 상호작용과 집단 간 변화에서는 유 의한차이가 없었다( $\mathrm{p}>0.05)($ Table 3$)$.

\section{고 찰}

본 연구는 20 대 건강한 성인 남녀 30 명을 대상으로 $\mathrm{KAG}$ 는 DOMS 유 발 전 키네시오 테이핑을 적용하고, $\mathrm{NTG}$ 는 적용하지 않은 상태에서 인위적인 DOMS를 유발한 후에 유발 24 시간 후, 48 시간 후, 72 시간 후 로 시기를 나누어 휴식과 운동 시 통증, 압통, 고유수용성감각, 근력 을 분석하였다. 편심성 운동으로 인해 발생되는 DOMS는 여러 부정 적인 증상을 발생시켜 일상생활동작에 제약을 유발하며, DOMS 관 련 증상이 발생된 후에 치료에만 집중하여 많은 비용과 시간이 소요 된다. 그러므로 예방이 가장 좋은 치료 방법이라 생각하여 키네시오 테이핑 적용이 DOMS에 의해 발생하는 증상에 미치는 영향을 연구 하기 위해 본 연구를 설계하였고 진행한 결과, 통증의 변화는 휴식 시 는 시기별에서만 유의한 차이가 있었다. 운동 시는 시기별, 시기와 군 간 상호작용, 집단 간 변화에서 유의한 차이가 발생하였고, 48 시간 후 와 72시간 후에서 $\mathrm{KAG}$ 와 NTG 두 집단에서 유의한 차이가 발생하였 다. Cordun과 Tecuceau ${ }^{27}$ 는 목 통증이 있는 환자 6 명을 대상으로 1주 일간 물리치료와 함께 적용한 테이핑이 마사지 적용보다 목의 통증 이 유의하게 감소하였다고 하였고, Goto과 Morishima ${ }^{28}$ 는 근육 손상 운동 후에 압박 의류 착용이 근기능의 빠른 회복과 통증 감소에 효과 적이라고 하였다. DOMS에 의한 통증과 테이핑 적용 연구는 아니지 만 선행연구와 비슷한 결과가 발생하였다. DOMS 메커니즘을 보면 근조직이 손상되어 발생하는 염증의 문제로써 ${ }^{29}$ 혈관의 생화학적 변 화로 인해 통증 물질들의 출현으로 통증이 발생한다. 염증과 통증간 의 관련성을 언급하기엔 부족하지만 키네시오 테이핑 적용이 피부의
반사운동을 유발하고 그로 인해 피부와 결합조직 사이의 혈액과 림 프의 순환을 증가시켜 ${ }^{30}$ 염증 정도를 최소화시키고 피부에 발생하는 자극으로 관문조절설(gate control theory)에 의해 통증이 최소화된 결 과로 생각된다. ${ }^{31}$ 사후분석 결과 DOMS가 발생한 하루가 지난 시점부 터 운동 시 통증이 NTG에 비해 적게 발생되었고 48시간과 72 시간에 서 통증 발생률이 감소되어 두 군의 차이가 있었다. 이러한 점을 보면 사전 테이핑 적용이 근육 조직을 보다 적게 손상시켜 염증을 최소화 시켰고 그로 인해 통증의 발생은 최소화가 되었으며 그 결과 NTG에 비해 48 시간만에 능동 근수축에 의해 발생하는 운동 시 통증이 감소 된 것으로 생각된다.

통증과 관련성이 깊은 압통의 변화는 시기별, 시기와 군 간 상호작 용에서 유의한 차이가 발생하였고, 72 시간 후 두 집단에서 유의한 차 이가 발생하였다. 테이핑은 적용 부위의 압력을 감소시키며 손상된 조직의 재생을 촉진시킨다. ${ }^{32}$ 이러한 변화는 통증 감소와 압통 역치 증가로 이어진다. ${ }^{33}$ Mahbobeh 등 ${ }^{34}$ 은 요추 추간판 탈출증 환자에게 근막이완요법을 적용한 후 압통 역치가 증가했다고 하였다. 적용 기 법은 다르지만 테이핑도 근막이완요법처럼 근육에 직접적으로 적용 하여 혈관의 변화를 유도하며 근육 내부 순환을 촉진하고, ${ }^{35}$ 손상된 근섬유의 회복을 시키는 것으로 알려져 있다. 사전 테이핑 적용이 지 속적인 감각자극을 주게 되어 이로 인한 감각 역치가 NTG에 비해 적 게 감소되었다고 생각된다. 집단 간 변화의 유의하지 않은 결과는 상 호작용의 효과가 주효과를 가리는 가면효과(masking effect)로 인한 결과로 해석된다. ${ }^{36}$

고유수용성감각 변화는 시기별, 시기와 군 간 상호작용, 집단 간 변 화에서 유의한 차이가 발생하였고, 72 시간 후 두 집단에서 유의한 차 이가 발생하였다. 고유수용성감각은 근육, 힘줄, 관절 수용기로부터 정보를 받아 관절과 근육을 무의식적으로 조절하며 대부분 근육 손 상에 의해 상실되며 DOMS가 고유수용성감각에 변화를 발생시켜 생체 회귀에 영향을 미친다. ${ }^{37}$ 특히 편심성 수축은 근육의 기계적 성 질(mechanical property)을 변화시키며 고유수용성감각을 감소시키 기 때문에 ${ }^{38}$ 본 연구에서 $\mathrm{KNG}$ 의 고유수용성감각 변화는 감소하였 고 테이핑 적용으로 인한 근 손상과 근육의 성질 변화는 최소화되어 고유수용성감각 변화가 감소되어 이러한 결과가 발생된 것으로 생각 된다.

근력 변화는 시기별에서만 유의한 차이가 있었다. 최근 키네시오 테이핑 관련 메타분석 결과 테이핑 적용이 근육의 힘을 증가시키기 않는다고 하였고, ${ }^{39}$ Lemos 등 ${ }^{40}$ 은 키네시오 테이핑은 개인의 근활동 을 용이하게끔 보완적인 도구로만 설계되어 근력의 이득은 발생하지 않는다고 하여 본 연구 결과와 비슷하였다. 근력은 최대 2주가 지나 야만 회복이 된다. ${ }^{9}$ 하지만 본 연구의 시기별 변화량을 보면 $\mathrm{KAG}$ 는 근력 감소는 NTG에 비해 적고 회복 기간도 72 시간만에 초기 근력의 
대부분을 회복한 것에 비해 NTG는 72시간이 지나도 초기 근력을 회 복하지 못하였다. 이러한 변화는 상호작용이나 집단 간 변화는 없었 지만 사전 테이핑 적용이 근육 손상을 최소화한 결과로 해석된다. 결 과적으로 사전 키네시오 테이핑 적용은 DOMS의 증상인 운동 시 통 증, 압통 고유수용성 감각에 관여하는 근기능 손상과 회복속도에 영 향을 미치며 테이핑 적용이 DOMS에 긍정적인 영향을 미친다는 것 을 알 수가 있었다.

본 연구는 특정 연령대와 소수의 대상자를 이용하였고 생체 내(in vivo)연구를 밝히지 못하여 연구 결과를 일반화하기에는 무리가 있 다. 하지만 키네시오 테이핑 적용이 DOMS에 미치는 효과는 긍정적 으로 생각하며 DOMS 관련 기초 자료와 임상에서 DOMS 예방을 위 한 중재 방법으로 유용할 것으로 생각된다. 후속 연구에서 대상자의 다변화와 본 연구에서 확인하지 못한 생체 내 변화 와 생화학적, 형태 학적 변화에 대한 연구가 필요하다고 생각한다.

\section{REFERENCES}

1. Hicks K, Onambélé G, Winwood K et al. Muscle damage following maximal eccentric knee extensions in males and females. PloS one. 2016; 11(3):e0150848.

2. Lima LC, Denadai BS. Attenuation of eccentric exercise-induced muscle damage conferred by maximal isometric contractions: a mini review. Front Physiol. 2015;6:300.

3. Nosaka K, Lavender A, Newton M et al. Muscle damage in resistance training. Int J Sport Health Sci. 2003;1(1):1-8.

4. Kisner C, Colby LA, Borstad J. Therapeutic Exercise: Foundations and Techniques. 7th ed. Philadelphia, F.A. Davis Company, 2017.

5. Radaelli R, Bottaro M, Wagner DR et al. Men and women experience similar muscle damage after traditional resistance training protocol. Isokinet Exerc Sci. 2014;22(1):47-54.

6. Miller PC, Bailey SP, Barnes ME et al. The effects of protease supplementation on skeletal muscle function and DOMS following downhill running. J Sports Sci. 2004;22(4):365-72.

7. McHugh MP, Connolly DA, Eston RG et al. Exercise-induced muscle damage and potential mechanisms for the repeated bout effect. Sports Med. 1999;27(3):157-70.

8. Cheung K, Hume PA, Maxwell L. Delayed onset muscle soreness. Sports Med. 2003;33(2):145-64.

9. Fridén J. Delayed onset muscle soreness. Encyclopedia of Pain, Springer, 2013:874-7.

10. Kim SJ, Kim YN, Lee KH et al. The influences of cryotherapy and intermittent compression on experimantal delayed onset muscle soreness. J Kor Phy Ther. 2001;13(3):653-64.

11. Nelson N. Delayed onset muscle soreness: Is massage effective? Journal of Bodywork and Movement Therapies. 2013;17(4):475-82.

12. Lee SY, Kim JY. The comparison of low intensity eccentric exercise and dynamic stretching on delayed onset muscle soreness. JKAIS. 2012; 13(10):4676-85.

13. Yoon CK, Lee J. Prevention and treatment of muscle damage induced by eccentric muscle contraction. Journal of Coaching Development. 2005; 7:35-45.

14. Cho NJ, Song SH. Effects of microcurrent delayed onset muscle soreness on creatine Kinase. KSIM. 2014;2(3):31-8.

15. Guimaraes B, Barreto J, Martins A et al. The role of tecar therapy in the delayed onset muscle soreness and functional recovery. Ann Phys Rehabil Med. 2018;61:e75-6.

16. Bae YS, Kim NS. The effect of Kinesio taping on delayed onset muscle soreness. J Kor Phy Ther. 2005;17(4):469-76.

17. Murray H, Husk L. Effect of Kinesio ${ }^{\mathrm{TM}}$ taping on proprioception in the ankle. J Orthop Sports Phys Ther. 2001;31:A-37.

18. Halseth T, McChesney JW, DeBeliso M et al. The effects of Kinesio ${ }^{\mathrm{TM}}$ taping on proprioception at the ankle. J Sports Sci Med. 2004;3(1):1-7.

19. Park YN, Bae YS. Change of pain and breathing function following Kinesio taping of myofascial pain in sternocleidomastoid muscle. J Kor Phy Ther. 2014;26(5):302-7.

20. Park SJ, Lee JH. Effect of joint mobilization and Kinesio taping on pain, range of motion, and knee function in patients with knee osteoarthritis. J Kor Phy Ther. 2016;28(5):279-85.

21. Rojhani-Shirazi Z, Amirian S, Meftahi N. Effects of ankle Kinesio taping on postural control in stroke patients. J Stroke Cerebrovasc Dis. 2015; 24(11):2565-71.

22. Koseoglu BF, Dogan A, Tatli HU et al. Can Kinesio tape be used as an ankle training method in the rehabilitation of the stroke patients?. Complement Ther Clin Pract. 2017;27:46-51.

23. Kase K, Wallis J, Kase T. Clinical therapeutic applications of the Kinesio taping method. 3rd ed. Albuquerque, Kinesio, 2003.

24. Behm DG, Baker KM, Kelland R et al. The effect of muscle damage on strength and fatigue deficits. J Strength Cond Res. 2001;15(2):255-64.

25. Wagner DR, Tatsugawa K, Parker D et al. Reliability and utility of a visual analog scale for the assessment of acute mountain sickness. High Alt Med Biol. 2007;8(1):27-31.

26. Jung DY, Koh EK, Kwon OY et al. Effect of medial arch support on displacement of the myotendinous junction of the gastrocnemius during standing wall stretching. J Orthop Sports Phys Ther. 2009;39(12):86774.

27. Mariana C, Carmen-Oana T. Massage versus kinesio taping possibilities to enhance the kinetic program in mechanically triggered neck pain. Procedia Soc Behav Sci. 2014;117:639-45.

28. Goto K, Morishima T. Compression garment promotes muscular strength recovery after resistance exercise. Med Sci Sports Exerc. 2014; 46(12):2265-70.

29. Halliwell B. Reactive species and antioxidants redox biology is a fundamental theme of aerobic life. Plant physiol. 2006;141(2):312-22.

30. Chang HY, Chou KY, Lin JJ et al. Immediate effect of forearm Kinesio taping on maximal grip strength and force sense in healthy collegiate athletes. Phys Ther Sport. 2010;11(4):122-7.

31. Chen PL, Hong WH, Lin CH et al. Biomechanics effects of Kinesio taping for persons with patellofemoral pain syndrome during stair climbing. 4th Kuala Lumpur International Conference on Biomedical Engineering. 2008;21:395-7.

32. Hammer WI. Functional Soft-Tissue Examination and Treatment by Manual Methods. 3rd ed. Burlington, Jones \& Bartlett Learning, 2007.

33. Kahanov L. Kinesio taping ${ }^{\circledR}$, part 1: an overview of its use in athletes. 
Athl Ther Today. 2007;12(3):17-8.

34. Mahbobeh S, Alireza M, Soheila Y et al. Effects of myofascial release technique on pain and disability in patients with chronic lumbar disc herniation: a randomized trial. Phys Med Rehab Kuror. 2017;27(04): 218-25.

35. Moraska AF, Hickner RC, Kohrt WM et al. Changes in blood flow and cellular metabolism at a myofascial trigger point with trigger point release (ischemic compression): a proof-of-principle pilot study. Arch Phys Med Rehabil. 2013;94(1):196-200.

36. Sung NK. Analysis and experiment of repetitive measurement. Paju, Free Academy, 1997:113.

37. Choi KH, Nam SN. Effects of the eccentric exercise induced delayed muscle soreness on proprioception, muscle strength and muscle fatigue. J Korea Soc Phys Ther. 2004;16(3):176-91.

38. Weerakkody N, Percival P, Morgan D et al. Matching different levels of isometric torque in elbow flexor muscles after eccentric exercise. Experimental brain research. Exp Brain Res. 2003;149(2):141-50.

39. Csapo R, Alegre LM. Effects of Kinesio ${ }^{\circledR}$ taping on skeletal muscle strength-a meta-analysis of current evidence. J Sci Med Sport. 2015; 18(4):450-6.

40. Lemos TV, de Souza Júnior JR, dos Santos MGRD et al. Kinesio taping effects with different directions and tensions on strength and range of movement of the knee: a randomized controlled trial. Braz J Phys Ther. 2018;22(4)283-90. 